\title{
Subclinical Right Ventricular Dysfunction in Patients with Severe Aortic Stenosis: A Retrospective Case Series
}

Dagmar F. Hernandez-Suarez • Angel López-Candales

Received: December 5, 2016/Published online: January 25, 2017

(C) The Author(s) 2017. This article is published with open access at Springerlink.com

\begin{abstract}
Introduction: There is scarce information about right ventricle (RV) function in patients with secondary pulmonary hypertension $(\mathrm{PH})$ undergoing transcatheter aortic valve implantation (TAVI). We aim to identify possible RV abnormalities in patients referred for TAVI with severe aortic stenosis (sAS) and secondary $\mathrm{PH}$.

Methods: Objective measures of RV function, as well as noninvasive estimates of pulmonary artery systolic pressures (PASP) were obtained from 30 sAS patients undergoing percutaneous valve intervention.

Results: Sixteen (53\%) evaluated patients had some degree of PH. As expected, left ventricular mass index $\left(281 \pm 75 \mathrm{~g} / \mathrm{m}^{2}\right)$ and left atrial volume index $\left(89 \pm 23 \mathrm{~mL} / \mathrm{m}^{2}\right)$ values were significantly elevated. Even though RV end-systolic $\left(8 \pm 4 \mathrm{~cm}^{2}\right)$ and end-diastolic $\left(17 \pm 4 \mathrm{~cm}^{2}\right)$ areas were normal as well as $\mathrm{RV}$ fractional area
\end{abstract}

Enhanced content To view enhanced content for this article go to http://www.medengine.com/Redeem/ E387F06022413BB8.

D. F. Hernandez-Suarez

Department of Medicine, University of Puerto Rico

School of Medicine, San Juan, Puerto Rico

A. López-Candales ( $₫)$

Cardiovascular Medicine Division, University of

Puerto Rico School of Medicine, San Juan, Puerto

Rico

e-mail: angel.lopez17@upr.edu change values $(57 \pm 16 \%)$; both longitudinal measures of RV systolic function such as tricuspid annular plane systolic excursion $(1.9 \pm 0.5 \mathrm{~cm})$ and systolic velocity $(10 \pm 2 \mathrm{~cm} /$ s) were clearly reduced with just mild elevations in PASP (54 $\pm 7 \mathrm{mmHg}$ ).

Conclusions: Subclinical RV dysfunction is present in patients with sAS and secondary $\mathrm{PH}$ undergoing TAVI. Whether longitudinal measures of RV systolic function could predict clinical outcomes in these patients needs to be further explored.

Keywords: Echocardiography; Pulmonary hypertension; Severe aortic stenosis; Subclinical right ventricular dysfunction

\section{INTRODUCTION}

Improved survival of the population has raised our attention to degenerative calcified aortic stenosis (AS), the most common form of acquired valvular heart disease in the Western world. Depending on the source, from 3\% to $7 \%$ of patients older than 65 years of age has a moderate to severe degree of AS; a prevalence that is projected to increase with aging of the population [1].

Since symptomatic severe AS is lethal with high 2-year mortality, surgical aortic valve replacement has been traditionally offered to these patients in order to improve survival. 
However, up to $50 \%$ of patients with symptomatic AS are usually not referred to a surgeon due to the presence of significant comorbidities [2]. Moreover, older age and left ventricular dysfunction have been reported as additional reasons for which patients were denied surgery rather than their associated comorbidities.

The advent of transcatheter aortic valve implantation (TAVI) procedures has broadened the opportunity to many patients to undergo this intervention if considered at high risk for traditional surgical replacement. In a recent review, surgery for AS and TAVI were compared and TAVI was found to have similar or better early and midterm outcomes for adults with AS, including those at low to intermediate risk [3]. Therefore, it is important to characterize better these patients in order to determine which patients would benefit the most.

Most recently, right ventricular (RV) dilatation has been associated with postoperative outcomes in patients undergoing TAVI. Furthermore, in inoperable AS patients treated with TAVI, the presence of moderate or severe tricuspid regurgitation and RV dilatation have been independently associated with increased 1-year mortality [4]. Finally, the presence of secondary pulmonary hypertension $(\mathrm{PH})$ and $\mathrm{RV}$ failure in AS patients has been also associated with an increased perioperative risk [5].

There is paucity of data regarding RV function in patients with severe AS and mild degrees of secondary $\mathrm{PH}$ being considered for possible TAVI. We, therefore, examined patients referred for TAVI to describe RV echocardiographic measurements to determine possible RV abnormalities in the presence of $\mathrm{PH}$ secondary to severe AS (sAS).

\section{METHODS}

In this retrospective case series, echocardiographic data from patients with sAS and preserved left ventricular systolic function from 2009 through 2011 were collected. This article is based on previously conducted studies and does not involve any new studies of human or animal subjects performed by any of the authors.
The University of Cincinnati College of Medicine Institutional Review Board Committee approved data collection for this study.

Inclusion criteria required that all patients at the time of the echocardiographic study were in normal sinus rhythm. In addition, there had to be good visualization of the left and right ventricular endocardium for tracing of end diastolic and systolic cavity. Patients with atrial fibrillation or rhythm abnormalities, mitral annular calcification, mitral valve stenosis, or previous valvular replacement surgery were excluded.

Two-dimensional echocardiographic studies were performed using commercially available systems (Vivid 7 and 9; GE Medical Systems, Milwaukee, WI, USA). The following echocardiographic parameters were measured: (A) aortic valve gradient and aortic dimensional index; (B) pulmonary artery systolic pressure (PASP); (C) LV ejection fraction, mass index, as well as end-systolic and end-diastolic volumes; (D) Left atrial volume index; (E) RV fractional area change, systolic velocity, end-systolic and end-diastolic area; (F) tricuspid annular plane systolic excursion (TAPSE), TA tissue Doppler systolic velocity (TA TDI s'), maximum tricuspid regurgitation velocity and right atrial pressure. The commercially available software Merge Cardio Workstation (Merge Healthcare) was used to calculate all echocardiographic measurements determined by a single observer. Categorical data are presented as frequencies and continuous data are presented as mean \pm standard deviation.

\section{RESULTS}

In this preliminary study, a complete transthoracic echocardiogram with adequate left and right endocardial border resolution to allow determination of end systolic and diastolic measurements as well as TA-motion with M-mode and tissue Doppler of tricuspid valve and inferior vena cava were performed in 30 patients [mean age $82 \pm 11$ years, 12 men $(40 \%)]$ with severe aortic stenosis. Ninety-seven percent of the study population were older than 65 years. After evaluating PASP 
measurements, we found that 16 (53\%) individuals had $\mathrm{PH}$.

Echocardiographic parameters of $\mathrm{PH}$ patients are listed in Table 1. The mean aortic valve gradient of the studied population was $56 \pm 20 \mathrm{mmHg}$ and the dimensional index was $0.2 \pm 0.1$. As expected, in this sAS patient population both left ventricular mass index $\left(281 \pm 75 \mathrm{~g} / \mathrm{m}^{2}\right)$ and left atrial volume index $\left(89 \pm 23 \mathrm{~mL} / \mathrm{m}^{2}\right)$ values were significantly elevated. RV end systolic $\left(8 \pm 4 \mathrm{~cm}^{2}\right)$ and end diastolic $\left(17 \pm 4 \mathrm{~cm}^{2}\right)$ areas, as well as RV fractional area change values were within the normal range $(57 \% \pm 16 \%)$. However, longitudinal measures of RV systolic function such as tricuspid annular plane systolic excursion $(1.9 \pm 0.5 \mathrm{~cm})$ and TA TDI s' $(10 \pm 2 \mathrm{~cm} / \mathrm{s})$ were clearly reduced with just mild elevations in PASP (54 $\pm 7 \mathrm{mmHg}$ ).

\section{DISCUSSION}

These preliminary results appear to suggest that subclinical RV dysfunction is present in sAS patients with mild degrees of $\mathrm{PH}$, which is clinically critical considering that $\mathrm{PH}$ is not only an independent predictor of late TAVI mortality [6], but also increases operative mortality while reducing long-term survival [7]. Furthermore, subclinical RV dysfunction has been identified as an adverse predictor of clinical outcomes in PH patients [8].

The prevalence of severe pulmonary hypertension in patients with severe aortic valve stenosis has been reported as high as $29 \%$ using invasive hemodynamic monitoring prior to surgical aortic valve replacement (SAVR) [9]. Recent data from Barbash et al., showed that pulmonary hypertension was a frequent co-morbidity found

Table 1 Echocardiographic data of the study population

\begin{tabular}{lcc}
\hline Variables & Mean value $( \pm \mathbf{S D})$ & Range \\
\hline Aortic valve gradient $(\mathrm{mmHg})$ & $56(20)$ & $28-99$ \\
Aortic dimensional index & $0.2(0.1)$ & $0.1-0.3$ \\
PASP $(\mathrm{mmHg})$ & $54(7)$ & $45-66$ \\
LVEF $(\%)$ & $66(19)$ & $32-92$ \\
LV-end systolic volume $\left(\mathrm{cm}^{3}\right)$ & $37(31)$ & $5-102$ \\
LV-end diastolic volume $\left(\mathrm{cm}^{3}\right)$ & $100(43)$ & $45-192$ \\
LV mass index $\left(\mathrm{g} / \mathrm{m}^{2}\right)$ & $281(75)$ & $175-437$ \\
LA volume index $\left(\mathrm{ml} / \mathrm{m}^{2}\right)$ & $89(23)$ & $46-130$ \\
RV-end systolic area $\left(\mathrm{cm}^{2}\right)$ & $8(4)$ & $4-19$ \\
RV-end diastolic area $\left(\mathrm{cm}^{2}\right)$ & $17(4)$ & $11-27$ \\
RV fractional area change $(\%)$ & $57(16)$ & $29-79$ \\
TAPSE $(\mathrm{cm})$ & $1.9(0.5)$ & $1.1-2.6$ \\
TA TDI s' $(\mathrm{cm} / \mathrm{s})$ & $10(2)$ & $6-13$ \\
MaxTR $(\mathrm{cm} / \mathrm{s})$ & $3.3(0.2)$ & $3.0-3.8$ \\
RAP $(\mathrm{mmHg})$ & $11(3)$ & $10-19$ \\
\hline
\end{tabular}

$P A S P$ pulmonary artery systolic pressure, $L V$ left ventricle, $L A$ left atrium, $R V$ right ventricle, TAPSE tricuspid annular plane systolic excursion, TA TDI 's tricuspid annular tissue Doppler imaging systolic velocity, MaxTR maximum tricuspid regurgitation velocity, $R A P$ right atrial pressure 
in patients with severe aortic stenosis referred for TAVR. In addition, these investigators found that significantly elevated pulmonary artery pressures at baseline was a poor prognostic factor when performing preprocedural assessment of the patients [10]. The prevalence of $\mathrm{PH}$ in our case series $(56 \%)$ was higher than previously published by these authors.

Musa and collaborators have recently explored the impact of TAVI and SAVR upon RV function in patients with sAS using cardiovascular magnetic resonance [11]. Interestingly, they found that TAVI had no adverse impact on RV function and volume. Unfortunately, we lack post-TAVI echocardiographic information for most of patients included in our study. Nevertheless, further studies are encouraged to determine whether or not TAVI has any adverse beneficial impact upon right ventricular echocardiographic parameters.

Even though there have been some variations in terms of what is expected as normal with regards to longitudinal measures of RV systolic function, our laboratory has consistently shown the linear relationship between these measures and RV fractional area change. In prior reported studies, a TAPSE $>2 \mathrm{~cm}$ and a TD TDI s' $>12 \mathrm{~cm} / \mathrm{s}$ correlated with a RV fractional area change $>55 \%[12,13]$.

Some limitations need to be acknowledged in our study. First, this is a retrospective case series study; however, the main goal was met. Second, there was only a small number of patients included for analysis. Third, the original database missed important data, such as strain imaging and invasive hemodynamic information. Furthermore, based on the pre-specified exclusion criteria no assumptions can be made on how atrial fibrillation or rhythm abnormalities, mitral annular calcification, mitral valve stenosis, or prior valvular replacement surgery could affect the reliability of our study findings.

\section{CONCLUSION}

Reductions in longitudinal measures of RV systolic function suggestive of subclinical RV dys- function could affect clinical outcomes in sAS patients, despite normal reference standard values for RV size and fractional area change in mild degrees of PH. Additional studies are now required to determine whether subclinical $\mathrm{RV}$ dysfunction in sAS patients with mild $\mathrm{PH}$ undergoing TAVI might not only be an indirect measurement of AS severity, but also an important tool in predicting overall clinical outcomes.

\section{ACKNOWLEDGEMENTS}

This publication was partially supported by the National Institute on Minority Health and Health Disparities of the National Institutes of Health Award Numbers CCTRECD-R25 MD007607 and HiREC-S21MD001830. Its contents are solely the responsibility of the authors and do not necessarily represent the official views of the National Institutes of Health. No funding was received for the publication charges associated with this article.

All named authors meet the International Committee of Medical Journal Editors (ICMJE) criteria for authorship for this manuscript, take responsibility for the integrity of the work as a whole, and have given final approval for the version to be published.

Disclosures. Dagmar F. Hernandez-Suarez and Angel López-Candales have nothing to declare.

Compliance with ethics guidelines. This article is based on previously conducted studies and does not involve any new studies of human or animal subjects performed by any of the authors. The University of Cincinnati, College of Medicine Institutional Review Board Committee approved data collection for this study.

Data availability. The datasets analyzed during the current study are available from the corresponding author on reasonable request. 
Open Access. This article is distributed under the terms of the Creative Commons Attribution-NonCommercial 4.0 International License (http://creativecommons.org/licenses/ by-nc/4.0/), which permits any noncommercial use, distribution, and reproduction in any medium, provided you give appropriate credit to the original author(s) and the source, provide a link to the Creative Commons license, and indicate if changes were made.

\section{REFERENCES}

1. Vahanian A, Baumgartner H, Bax J, et al. Guidelines on the management of valvular heart disease: the Task Force on the Management of Valvular Heart Disease of the European Society of Cardiology. Eur Heart J. 2007;28(2):230-68.

2. Lung B, Cachier A, Baron G, et al. Decision-making in elderly patient with severe aortic stenosis: why are so many denied surgery? Eur Heart J. 2005;26(24):2714-20.

3. Gargiulo G, Sannino A, Capodanno D, et al. Transcatheter aortic valve implantation versus surgical aortic valve replacement: a systematic review and meta-analysis. Ann Intern Med. 2016;165(5):334-44.

4. Lindman BR, Maniar HS, Jaber WA, et al. The effect of tricuspid regurgitation and the right heart on survival after transcatheter aortic valve replacement: insights from the PARTNER II Inoperable Cohort. Circ Cardiovasc Interv. 2015;8(4):e002073. doi:10.1161/CIRCINTERVENTIONS.114.002073.

5. Pai RG, Varadarajan P, Kapoor N, Bansal RC. Aortic valve replacement improves survival in severe aortic stenosis associated with severe pulmonary hypertension. Ann Thorac Surg. 2007;84(1):80-5.

6. Luçon A, Oger E, Bedossa M, et al. Prognostic implications of pulmonary hypertension in patients with severe aortic stenosis undergoing transcatheter aortic valve implantation: study from the FRANCE 2 registry. Circ Cardiovasc Interv. $2014 ; 7(2): 240-7$.

7. Zlotnick DM, Ouellette ML, Malenka DJ, et al. Effect of preoperative pulmonary hypertension on outcomes in patients with severe aortic stenosis following surgical aortic valve replacement. Am J Cardiol. 2013;112(10):1635-40.

8. López-Candales A, Lopez FR, Trivedi S, Elwing J. Right ventricular ejection efficiency: a new echocardiographic measure of mechanical performance in chronic pulmonary hypertension. Echocardiography. 2014;31(4):516-23.

9. Silver K, Aurigemma G, Krendel S, Barry N, Ockene I, Alpert J. Pulmonary artery hypertension in severe aortic stenosis: incidence and mechanism. Am Heart J. 1993;125:146-50.

10. Barbash IM, Escarcega RO, Minha S, et al. Prevalence and impact of pulmonary hypertension on patients with aortic stenosis who underwent transcatheter aortic valve replacement. Am J Cardiol. 2015;115(10):1435-42.

11. Musa TA, Uddin A, Fairbairn TA, et al. Right ventricular function following surgical aortic valve replacement and transcatheter aortic valve implantation: a cardiovascular MR study. Int J Cardiol. 2016;223:639-44.

12. López-Candales A, Rajagopalan N, Gulyasy B, Edelman K, Bazaz R. Comparative echocardiographic analysis of mitral and tricuspid annular motion: differences explained with proposed anatomic-structural correlates. Echocardiography. 2007;24(4):353-9.

13. Bazaz R, Edelman K, Gulyasy B, López-Candales A. Evidence of robust coupling of atrioventricular mechanical function of the right side of the heart: insights from M-mode analysis of annular motion. Echocardiography. 2008;25(6):557-61. 